\title{
Translation, Cultural Adaptation and Validation of General Medication Adherence Scale (GMAS) into the Nepalese Language
}

\author{
Rajeev Shrestha $\mathbb{D}^{1, *}$ \\ Binaya Sapkota (iD) ${ }^{2, *}$ \\ Asmita Priyadarshini \\ Khatiwada (iD ${ }^{3}$ \\ Sunil Shrestha iD ${ }^{4, *}$ \\ Saval Khanal (iD ${ }^{5}$ \\ Bhuvan KC (iD ${ }^{4}$ \\ Vibhu Paudyal (iD ${ }^{6}$ \\ 'Department of Pharmacy, District \\ Hospital Lamjung, Besisahar, Province \\ Gandaki, Nepal; ${ }^{2}$ Department of \\ Pharmaceutical Sciences, Nobel College, \\ Affiliated to Pokhara University, \\ Kathmandu, Province Bagmati, Nepal; \\ ${ }^{3}$ Department of Pharmaceutical and \\ Health Service Research, Nepal Health \\ Research and Innovation Foundation, \\ Lalitpur, Province Bagmati, Nepal; \\ ${ }^{4}$ School of Pharmacy, Monash University \\ Malaysia, Bandar Sunway, Selangor, 47500, \\ Malaysia; ${ }^{5}$ Division of Health Sciences, \\ Warwick Medical School, University of \\ Warwick, Coventry, UK; ' Institute of \\ Clinical Sciences, College of Medical and \\ Dental Sciences, University of \\ Birmingham, Birmingham, UK \\ *These authors contributed equally to this \\ work
}

Correspondence: Rajeev Shrestha Department of Pharmacy, District Hospital Lamjung, Besisahar, Province Gandaki, Nepal

Tel +977-9845445205

Email rajiv2stha@gmail.com

Binaya Sapkota

Department of Pharmaceutical Sciences,

Nobel College, Affiliated to Pokhara

University, Kathmandu, Province Bagmati,

Nepal

Tel +977-985 I I 34925

Email sapkota.binaya@gmail.com
Background: The General Medication Adherence Scale (GMAS) evaluates intentional and unintentional behaviour of patients, disease and medication burden and cost-related burden associated with non-adherence. GMAS was developed and validated among Urdu-speaking patients with chronic diseases. However, validated tool in Nepalese language to measure medication adherence among chronic illness patients currently does not exist.

Aim: To translate, culturally adapt, and validate the English version of GMAS into the Nepalese language to measure medication adherence among chronic illness patients.

Methods: The study was conducted among patients with chronic diseases in both hospital and community pharmacies of Nepal. The International Society for Pharmacoeconomics and Outcomes Research (ISPOR) Good Practice Guideline for linguistic translation and cultural adaptation was used to translate and culturally adapt the English version of GMAS into the Nepalese version. The translated version was validated amongst patients with chronic diseases in Nepal. Exploratory factor analysis was carried out using principal component analysis with varimax rotation. Test-retest reliability and internal consistency were analysed. Results: A total of 220 (53.6\% females, and 51.4\% of 51 to 70 aged patients) patients with chronic diseases participated in the study. The majority of patients took two medications $(27.3 \%)$ from six months to five and half years $(68.2 \%)$. Kaiser Meyer Olkin was found to be 0.83 . A principal axis factor analysis was conducted on the 3 items of GMAS without and with orthogonal rotation (varimax). The scree plot showed an inflexion on the third item that meant three components were present. The overall Cronbach's alpha value of the full-phase study was 0.82 .

Conclusion: The General Medication Adherence Scale was successfully translated into the Nepalese language, culturally adapted, and validated amongst chronic diseases patients of Nepal. Therefore, the GMAS-Nepalese version can be used to evaluate medication adherence among Nepalese-speaking patients with chronic disease.

Keywords: adherence, chronic disease, general medication adherence scale, GMAS, Nepal, psychometric validation

\section{Introduction}

Patient adherence to prescribed medications is crucial for a better health outcome. Adherence to therapy after beginning the medication treatment determines the ultimate clinical outcomes in patients. According to the World Health Organization (WHO), ${ }^{1}$ medication adherence is the extent to which a person's behaviour - taking medication, following a diet, and/or executing lifestyle changes, corresponds with agreed recommendations from a health care provider. 
Unfortunately, patients became non-adherent to their medication unintentionally or intentionally at times.

Medication non-adherence is responsible for 125,000 preventable deaths, $50 \%$ of treatment failure, and up to $25 \%$ of hospital admissions in the US alone. ${ }^{2}$ It is estimated that almost half of patients suffering from chronic diseases are not adherent to their medicines, and after a year, half of the adherent patients become non-adherent again. ${ }^{3}$ Noncommunicable diseases (NCDs) cause more than two-thirds (70\%) deaths globally and $82 \%$ of premature deaths (before 70 years) in low-and middle-income countries (LMICs). ${ }^{4}$ Similarly, NCDs caused two thirds $(66 \%)$ of total deaths in Nepal in 2017 AD. ${ }^{5}$ Furthermore, more than half of patients with the chronic disease showed poor adherence to their medicines in Nepal. ${ }^{6-9}$ NCDs require long-term adherence to their medication. Non-adherent to medication not only deteriorates the patient health condition and increases the risk of treatment failure but it also increases unnecessary hospital visits and financial burden to patients and the healthcare system. ${ }^{10-12}$ Whereas medication adherence reduces healthcare expenditure and improves healthcare utilisation. ${ }^{1,13,14}$ The success of pharmacotherapy is based on prescribing the right dose of the right medication and the patient adhering to that prescribed regimen. This is a vital factor for drug therapy's success, and achieving patient's medication adherence to the therapy is a leading challenge. ${ }^{15}$ Hence, measuring the patient's adherence is essential to audit the adherence problem and improve medication adherence errors identified.

Although numerous medication adherence tools are available, self-reporting measurement tools are mainly used and preferred. ${ }^{16,17}$ However, not even one self-administered scale is considered as a standard tool for measuring medication adherence. The selection of adherence measurement tools depends on the tool's factors or determinants and their validity. ${ }^{18}$ In Nepal, $18.7 \%$ of the population is still below the poverty line, and most people (63.4\%) pay out of pocket for healthcare and medicines. ${ }^{19,20}$ Thus, non-adherence to treatment, especially for chronic health conditions, can add more financial problems to the population living under financial distress. $^{21}$

Similarly, previous studies regarding medication adherence in Nepal also showed a significant positive association between medicine cost or family income with medication non-adherence. ${ }^{7,22}$ Therefore, it became essential to understand people's adherence using the tool that covers the economic determinants for improving medication adherence. Additionally, currently available tools, such as Morisky
Medication Adherence Scale (MMAS), ${ }^{23}$ Brief Medication Questionnaire (BMQ), ${ }^{24}$ Adherence to Refills and Medications Scale (ARMS), ${ }^{25}$ Medication Adherence Report Scale (MARS), ${ }^{26}$ Hill-Bone Compliance, ${ }^{27}$ have been developed in high-income countries with different socioeconomic and cultural settings and it may not be suitable for Nepalese context. Although there is no gold standard scale to measure the medication adherence scale, selfreported tools have often been criticised for not incorporating patient's behaviour-related non-adherence, cost-related nonadherence and complex overestimated adherence. ${ }^{18,28,29}$ Development and validation of tools using exploratory research undertaken in LMICs considering cultural barriers and facilitators to medication adherence are likely to capture reasons and extent of non-adherence in the population of Nepal.

General Medication Adherence Scale (GMAS) was a self-reported tool developed in 2018 in Pakistan, ${ }^{30}$ one of the geographically close LMICs in South Asia to Nepal and validated among chronic disease patients with all four types (content, face, criterion-related and construct) of validity methodology. ${ }^{30,31}$ It comprises a wide range of constructs, such as intentional and unintentional behaviour of patients, disease and medication burden and cost-related burden associated with non-adherence essential to LMICs like Nepal. ${ }^{28,31}$

Currently, there is a lack of self-reported medication adherence tool translated and psychometrically validated in the Nepalese language for patients with chronic diseases, including GMAS. Furthermore, the previously used tool for measuring adherence in Nepal is not translated into the Nepalese language, culturally adapted, and validated among chronic disease patients with construct validity using factor analysis. ${ }^{6-8,32}$ The English version of GMAS was previously formulated, ${ }^{31}$ but the Nepalese version of GMAS was necessary as not all Nepalese patients are fluent in reading, understanding and responding to scale in English. Therefore, translation, cultural adaptation, and validation into the Nepalese language are essential to facilitate and suit the Nepalese population context. Currently, there is a common practice of translation and validation. ${ }^{33,34}$ Therefore, this study aims to translate the English version of GMAS into Nepalese version and validate among patients with the chronic disease of Nepal. The Nepalese version of GMAS will help study medication adherence among Nepalese-speaking people scattered both inside and outside of Nepal, outside such 
as in India, where 8 million Nepalese people are supposed to be living. ${ }^{35}$

\section{Methods}

\section{Study Design and Setting}

The study was methodological and cross-sectional in design. It involved translating the English version of GMAS developed by Naqvi et al, ${ }^{30}$ culturally adapt it and verify its reliability and validity among the chronic disease patients of Nepal to measure their medications adherence. The study tool was designed to be selfadministered by the patient. All the methods were carried out following relevant guidelines and regulations for translation, cultural adaptation and validation. ${ }^{36,37}$

\section{Study Site, Study Population and Study Duration}

The study was carried out in pharmacies (hospital and community) of Kathmandu valley, Nepal. Kathmandu valley comprises three districts, namely, Bhaktapur, Kathmandu and Lalitpur. These three cities are the major metropolitan city of Nepal, where people come across the nation and live for their education, occupation and business. ${ }^{38}$ Data from these places are more representative and generalisable than from other parts of Nepal. For both pilot and full-phase studies, patients with chronic disease visiting the pharmacies to refill their regular medicines were conveniently approached and selected. Patients' verbal and written consent was taken before recruiting them into this study. Patients with chronic diseases, patients purchasing their chronic disease medications and native Nepalese speakers were the inclusion criteria for both pilot and full-phase studies. Patients receiving free medicines were excluded from the study. The data was collected from September 2020 to December 2020.

\section{Instruments}

GMAS was initially developed by Naqvi et al in the Urdu language and later translated and validated to English Language. ${ }^{30,31}$ Factor analysis was also carried out to replicate the factor structure for validity. ${ }^{31}$ The tool was used to study medication adherence in patients with chronic diseases. ${ }^{39,40}$ The self-report GMAS consists of 11 questionnaires divided into three categories. Patient Behaviour related Non-Adherence (PBNA) contains five questions, Additional Disease and Pill Burden related non-adherence (ADPB) contains four questions and Cost Related Non-
Adherence (CRNA) contains two questions. Likert scale labelled as "Always", "Mostly", "Sometimes", and "Never" was used to measure the response to the questionnaires.

Patient's demographic information and medicationrelated questions were also added to the questionnaire. Patient demographics covered participant's age, gender, ethnicity, educational qualification, marital status, occupation, and financial income. Medication-related questions included types of chronic illness, length of treatment, and the number of medications.

\section{Step I - Translation Procedure and Cultural Adaptation}

The English version of GMAS was translated into the Nepalese version. Before the translation, formal approval to translate the tool was obtained from the developer authors (\#090220-N). The translation and cultural adaptation process followed the standard protocol of the International Society for Pharmacoeconomics and Outcomes Research (ISPOR) Good Practice Guidelines for linguistic and cultural adaptation and validation. ${ }^{37}$ The process was carried out in the following five stages and presented in figure (Figure 1).

\section{Forward Translation}

Two native Nepalese speakers (FT1 and FT2) translated the English version of GMAS into the Nepalese language. Both were native Nepalese speakers, fluent in the English language and had a professional pharmacy degree. Afterwards, the translation coordinator (TC) compared and merged two forward translations into one reconciled version.

\section{Backward Translation}

Two independent backward translators (BT1 and BT2) as above were fluent in English, and Nepalese translations carried the reverse translation of reconciled forward translation into English. The back translators were blinded to the original English version.

\section{Review and Interim Version}

The TC formed an expert committee comprising of pharmacy academicians who had previous experience in translation. These experts were native Nepalese but were teaching students in English-speaking countries. Experts then investigated the reconciled back translation with the original English version and finalised an interim version for pilot testing. 


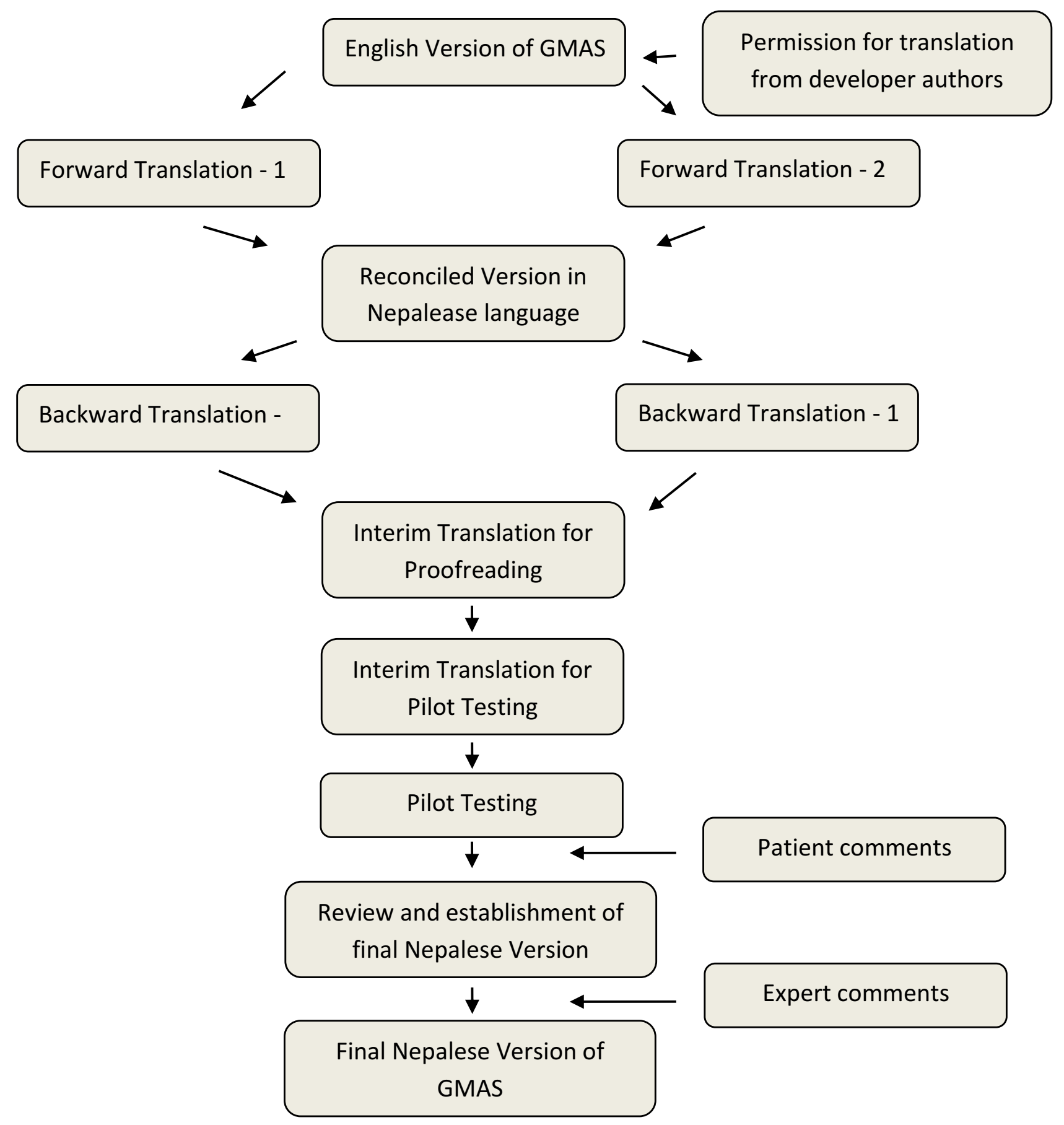

Figure I Stepwise translation procedure.

\section{Pilot Testing}

The interim translation was taken for the pilot study among 30 patients with chronic disease to ensure the proper comprehension of each question, acceptability, and cultural appropriateness of the translations. The pilot testing was done in a purposely selected hospital pharmacy. The patients visiting the hospital pharmacy were randomly approached and selected based on their interest in participating in pilot testing. The verbal and written consent of patients were taken before collecting their responses. The participants were asked to provide feedback on the clarity and wording of the questionnaires. Any misunderstanding, ambiguity, inappropriateness, and problematic wording reported by participants were recorded 
for further correction. Furthermore, the test-retest reliability of the patient response was also carried out at two weeks intervals to add rigour to the development of the translated tool.

\section{Final Version}

In the final step, the patients' comments and suggestions were examined before finalisation. Considering the comments and suggestions from pilot study participants, the wording and language were edited to suit the cultural relevance of the translation. Furthermore, the final translation was transferred to the expert team to review and correct the typographic, grammatical errors, and discrepancies between the original and translated versions. After consultation with experts, a final Nepalese version of GMAS was prepared with appropriate correction in the interim version. Finally, the final version was further processed for the validity study.

\section{Step 2 - Validation and Reliability Analysis Face Validity}

The face validity of the tool was carried out among 30 patients in the initial pilot study. In addition, a selfadministered interim version of GMAS questionnaires was given to chronically ill patients. They were asked to respond to the questionnaires and provide comments on the clarity, appearance, and suitability of the tool to measure medication adherence. Also, they were requested to provide suggestions for an appropriate and straight forward way to ask questions. The patients' suggestions and comments were taken into consideration for finalising the tool.

\section{Content Validity}

The tool, in its original language, was evaluated for content validity. ${ }^{30}$ The GMAS scale has already been used to evaluate medication adherence in different chronic disease patients. ${ }^{39,40}$ Therefore, we did not perform content validation, considering that it already owned content validity.

\section{Statistical Analysis}

Descriptive statistics were used, and the result is presented in terms of frequencies and percentages. Construct validity of the GMAS translated tool was assessed by using Principal Component Analysis (PCA). PCA was performed to establish which linear components existed within the data and how a particular variable contributed to that component. In addition, Kaiser-Meyer-Olkin (KMO) and sphericity tests were conducted before undergoing PCA to establish the evidence of sample sufficiency.

The test-retest reliability test was performed using Cronbach's alpha test. The internal consistency of the fullphase study data was also measured using Cronbach's alpha coefficient. The data analysis was done with the $\mathrm{R}$ version 4.03.3; R studio version 1.3.1093; package: corpcor. $^{41}$

\section{Data Collection Process}

The patients with chronic disease visiting the selected community and hospital pharmacies of Kathmandu valley for receiving their regular chronic disease medicines were approached to participate in the study. Based on patient's interest and approval to take part, they are selected. The objective, process, and participants' roles were explained verbally. After taking both verbal and written consent, data were collected. Additionally, they were assured about the confidentiality of their information. Once the requisite patient number was reached, the data collection process was stopped. Pharmacy service providers gave the data collection form to patients for self-completion. For patients who could not read and write, pharmacy service providers (pharmacist or pharmacy assistant working in a particular pharmacy) assisted in copying patient's responses by asking those questionnaires as a proxy or allowing the patient's caretaker to fill the data collection form.

\section{Sample Size Calculation}

The sample size for the statistical validation was calculated based upon the item response theory. The 1:20 item-torespondent ratio or a minimum of 200 samples is considered an appropriate sample size. ${ }^{42,43}$ Therefore, we selected 220 samples for 11-item questions based on the methodology used in the previous translation process of GMAS into the Arabic language. $^{44}$

\section{Ethical Consideration}

Ethical approval was taken from the Institutional Review Committee (IRC) of Nobel College, Kathmandu, Nepal (Ref No.: EPY IRC 2001/2020). The study was conducted in accordance with the guideline of the declaration of Helsinki. Written approval from the tool developer author was also taken before undergoing the translation process. Written and verbal informed consent of participating patients was taken before collecting data from them. Besides, consent from the experts was also taken to involve them in the review committee. 


\section{Results}

\section{Participant's Characteristics}

More than half of the participants $(51.4 \%, n=113)$ were aged $51-70$ years and the majority of them $(53.6 \%, \mathrm{n}=$ $118)$ were female. Most of the participants (32.3\%) lacked

Table I Demographic Characteristics of Study Population $(\mathrm{N}=$ 220)

\begin{tabular}{|c|c|}
\hline Variables & Frequency (\%) \\
\hline \multicolumn{2}{|l|}{ Age of the participants (in years) } \\
\hline Below 30 & $12(5.5)$ \\
\hline 30 to 50 & $47(21.4)$ \\
\hline 51 to 70 & $113(5 \mid .4)$ \\
\hline$>70$ & $48(21.8)$ \\
\hline \multicolumn{2}{|l|}{ Gender } \\
\hline Male & $102(46.4)$ \\
\hline Female & $118(53.6)$ \\
\hline \multicolumn{2}{|l|}{ Education } \\
\hline Uneducated & $71(32.3)$ \\
\hline Primary ( 5 year of formal schooling) & $54(24.5)$ \\
\hline Secondary ( 10 years of formal schooling) & $43(19.5)$ \\
\hline Higher secondary ( 12 years of formal schooling) & $22(10.0)$ \\
\hline Undergraduate & $23(10.5)$ \\
\hline Post-Graduate & $7(3.2)$ \\
\hline \multicolumn{2}{|l|}{ Employment status } \\
\hline Employed & $35(15.9)$ \\
\hline Unemployed & $13(5.9)$ \\
\hline Retired & $37(16.8)$ \\
\hline Household & $115(52.3)$ \\
\hline Self-employed & $20(9.1)$ \\
\hline \multicolumn{2}{|l|}{ Monthly Income (NPR) } \\
\hline$<20,000$ & $74(33.6)$ \\
\hline 20,000 to 40,000 & $103(46.8)$ \\
\hline 40,001 to 60,000 & $32(14.5)$ \\
\hline$>60,000$ & II (5.0) \\
\hline
\end{tabular}

Abbreviation: NPR, Nepalese Rupees (I United States Dollar = II5 NPR approximately on 22 Jan 2021). formal education and were not employed outside but were doing household chores (52.3\%). Less than half of the patients $(46.8 \%)$ had income ranging from 20,000 to 40,000 Nepalese rupees (Table 1).

About two-thirds of the participants took the medication for their health problems over the last 0.6 to 5.5 years. Besides, single medications were frequently used by chronic disease patients $(28.6 \%)$, followed by two $(27.3 \%)$ and four $(15 \%)$ different medications. Patients had up to three comorbid conditions, with two chronic illnesses being the most observed (58.2\%) (Table 2). Moreover, hypertension was the most common disease among the study participants. The details of the participants' diseases with the International Classification of Diseases (ICD) and disease frequencies were given in $\underline{\text { Supplementary Table } 1 \text { (see Supplementary file). }}$.

\section{Participants' Response to GMAS}

The GMAS questionnaire consisted of 11 questions in total, and each question had four different options to choose as an answer. GMAS1 and GMAS2 had a more significant number of answers in the "sometimes" option, while the rest of the other items had "Never" as a frequent answer. Likewise, if we consider the answer options with a smaller number of responses, GMAS1 had "Mostly", and rest of the other study items had "Always" (Table 3).

\section{Sampling Adequacy and Sphericity}

Since the KMO statistic was 0.83 (ie, $>0.6$ ), it indicated that the sample size was adequate for factor analysis. Furthermore, the p-value Bartlett test of homogeneity of variances (sphericity) was $<0.05$, which reflect that the variance was different for the various GMAS components from 1 to 11. Also, the significant Bartlett test result indicated that correlations between items were sufficiently large for PCA (see Supplementary file).

\section{Principal Component Analysis}

The Sums of Squared loadings (eigenvalues) showed that the three components (factors) had eigenvalues $>1$. So, these three components were extracted per the Kaiser's criterion, as $<30$ variables in the GMAS questionnaire and communalities were all $>0.7$. Thus, these factors, in combination, explained $57 \%$ of the variance (Table 4 ).

Hence, PCA was conducted on these three items of GMAS without and with orthogonal rotation (varimax) (Table 5). 
Table 2 Treatment-Related Characteristics Among the Study Participants

\begin{tabular}{|l|l|}
\hline Variables & Frequency (\%) \\
\hline \multicolumn{2}{|l|}{ Treatment length (in years) (Mean \pm SD: $5.26 \pm 4.41)$} \\
\hline$</=0.5$ & $2(0.9)$ \\
\hline $0.6-5.5$ & $150(68.2)$ \\
\hline $5.6-10.5$ & $45(20.5)$ \\
\hline $10.6-15.5$ & $13(5.9)$ \\
\hline $15.6+$ & $10(4.5)$ \\
\hline Medication number: (Mean \pm SD: $2.65 \pm 1.53)$ \\
\hline 1 & $63(28.6)$ \\
\hline 2 & $60(27.3)$ \\
\hline 3 & $32(14.5)$ \\
\hline 4 & $33(15.0)$ \\
\hline 5 & $23(10.5)$ \\
\hline 6 & $6(2.7)$ \\
\hline 7 & $3(1.4)$ \\
\hline Number of Chronic Illness (Mean \pm SD: $1.9 \pm 0.7)$ \\
\hline 1 & $49(22.3)$ \\
\hline 2 & $128(58.2)$ \\
\hline 3 & $43(19.5)$ \\
\hline
\end{tabular}

None of the variables created any problem since the R-matrix's determinant was 0.05119 (ie, >0.00001). Therefore, all questions or items in the GMAS scale correlated well with all others, and none of the correlation coefficients was substantial. Therefore, we would not eliminate any items at this stage (see Supplementary file).

\section{Scree Test}

The scree plot showed that there was an inflexion in the third item. As a result, three components were retained (see Supplementary file).

\section{Reliability Test}

The test-retest reliability analysis of pilot study showed that all the test-retest Cronbach's alpha values were greater than 0.88 (ie 88\%) and the composite Cronbach's alpha value was 0.894 (i.e, 89.4\%). Therefore, all the testretest values were reliable as these were in the range
(0.84-0.90) as described by Taber et al. ${ }^{45}$ In the above table, GMAS4_test, GMAS4_retest, GMAS6_test and GMAS11_test items could be deleted from the scale to improve their reliability as these had Cronbach's alpha values greater than the composite alpha value (Table 6).

The overall alpha value of 0.82 indicated that GMAS scale was reliable, and the present test was $80 \%$ consistent/ reliable in measuring the same construct. Since deleting any items did not increase Cronbach's alpha (that means, improve reliability), no item should have been deleted. Since all the values of r.drop were $>0.3$, all items correlated very well with the overall scale as required, and all items positively contributed to the overall reliability (Table 7).

\section{Discussion}

The GMAS was initially developed and validated in the Urdu-speaking patients patients with chronic illness in Pakistan, which was later translated and validated into English and Arabic languages. ${ }^{30,31,44}$ In the present study, the English version of GMAS was translated into Nepalese version, culturally adapted and validated among Nepalese patients with chronic diseases. Patients with hypertension, type 2 diabetes mellitus, COPD, and a combination of these diseases were involved throughout the process. According to the standard approved methodology (ISPOR) guideline, ${ }^{37}$ the comprehensibility, cultural applicability and simplicity of the tool were evaluated during the translation and cultural adaptation and corrected from the feedback of pilot study participants and experts in the translation process.

To ensure generalisation of result and minimise errors, sufficient sample size was required. Therefore, the study used the 1:20 item ratio of the sample as a reference to select a sample size for the validation study. Furthermore, KMO and Bartlett's test was conducted to measure the sample adequacy and sphericity. The test showed sufficiency of sample and suitability for following factorial analysis with KMO value 0.83 and Bartlett's test p-value $<0.05{ }^{46,47}$ The KMO value was comparatively close to 1 in our test, which is similar to Naqvi et al (0.832) in which the English version of GMAS was validated but slightly greater than the developer study (0.8) where GMAS scale was formulated and validated in the Urdu language. ${ }^{30,31}$

For structural validity, the most common PCA method was applied. Similar to the result of previous validation studies of GMAS, this study also showed a scale of three factors. ${ }^{31,44,48}$ According to Kaiser's criteria, three factors 
Table 3 GMAS Related Characteristics Among the Study Participants

\begin{tabular}{|c|c|c|c|c|c|c|}
\hline \multirow[t]{2}{*}{ Construct } & \multirow[t]{2}{*}{ Study Items } & \multicolumn{4}{|c|}{ Frequency (\%) } & \multirow[t]{2}{*}{ Total } \\
\hline & & Always & Mostly & Sometimes & Never & \\
\hline \multirow[t]{5}{*}{ PBNA } & GMASI & $20(9.1)$ & $9(4.1)$ & 101 (45.9) & $90(40.9)$ & $220(100)$ \\
\hline & GMAS2 & $3(1.4)$ & $14(6.4)$ & $118(53.6)$ & $85(38.6)$ & $220(100)$ \\
\hline & GMAS3 & $7(3.2)$ & $23(10.5)$ & $36(16.4)$ & 154 (70) & $220(100)$ \\
\hline & GMAS4 & $3(1.4)$ & $19(8.6)$ & $45(20.5)$ & $153(69.5)$ & $220(100)$ \\
\hline & GMAS5 & $3(1.4)$ & $8(3.6)$ & $42(19.1)$ & $167(75.9)$ & $220(100)$ \\
\hline \multirow[t]{4}{*}{ ADPB } & GMAS6 & I $(0.5)$ & $4(1.8)$ & $34(15.5)$ & $|8|(82.3)$ & $220(100)$ \\
\hline & GMAS7 & $2(0.9)$ & $14(6.4)$ & $65(29.5)$ & $139(63.2)$ & $220(100)$ \\
\hline & GMAS8 & $2(0.9)$ & $13(5.9)$ & $30(13.6)$ & $175(79.5)$ & $220(100)$ \\
\hline & GMAS9 & $3(1.4)$ & $6(2.7)$ & $49(22.3)$ & $162(73.6)$ & $220(100)$ \\
\hline \multirow[t]{2}{*}{ CRNA } & GMASIO & $4(1.8)$ & $4(1.8)$ & $26(11.8)$ & $186(84.5)$ & $220(100)$ \\
\hline & GMASII & $2(0.9)$ & $13(5.9)$ & $54(24.5)$ & I5I (68.6) & $220(100)$ \\
\hline
\end{tabular}

Abbreviations: PBNA, Patient behaviour related non-adherence; ADPB, Additional disease and pill burden; CRNA, Cost related non-adherence.

are confirmed since the eigenvalue is greater than $1 .{ }^{49}$ For $\quad$ confirmation, an additional test called scree test, not tested

Table 4 Principal Components Analysis Before Factor Retention on the Unrotated Condition

\begin{tabular}{|c|c|c|c|c|c|c|c|c|c|c|c|c|c|}
\hline Items & PCI & PC2 & PC3 & PC4 & PC5 & PC6 & PC7 & PC8 & PC9 & PCIO & PCII & h2 & u2 (ie, I-h2) \\
\hline GMASI & 0.56 & 0.10 & 0.60 & 0.07 & 0.11 & 0.18 & 0.16 & -0.42 & 0.09 & 0.22 & -0.08 & 1 & $-4.4 \times 10-16$ \\
\hline GMAS2 & 0.51 & -0.08 & 0.62 & -0.33 & 0.01 & -0.12 & 0.17 & 0.41 & 0.06 & -0.14 & 0.09 & 1 & $-1.6 \times 10-15$ \\
\hline GMAS3 & 0.48 & 0.47 & -0.23 & -0.01 & 0.27 & -0.62 & 0.16 & -0.05 & 0.03 & 0.09 & 0.03 & 1 & $7.8 \times 10-16$ \\
\hline GMAS4 & 0.51 & 0.41 & -0.33 & -0.42 & 0.08 & 0.41 & -0.10 & 0.17 & 0.18 & 0.22 & 0.05 & 1 & $3.3 \times 10-16$ \\
\hline GMAS5 & 0.58 & 0.52 & 0.01 & 0.33 & 0.13 & 0.27 & 0.05 & 0.07 & -0.30 & -0.30 & -0.07 & 1 & $3.3 \times 10-16$ \\
\hline GMAS6 & 0.70 & -0.24 & -0.29 & -0.17 & -0.01 & 0.04 & 0.10 & -0.27 & 0.31 & -0.38 & 0.00 & 1 & $4.4 \times 10-16$ \\
\hline GMAS7 & 0.72 & 0.04 & 0.19 & 0.13 & -0.12 & -0.13 & -0.58 & -0.09 & 0.00 & -0.02 & 0.24 & 1 & 1 \\
\hline GMAS8 & 0.77 & -0.07 & -0.05 & -0.13 & $-0.4 \mathrm{I}$ & -0.16 & -0.12 & 0.07 & -0.10 & 0.07 & -0.41 & I & $1.1 \times 10-16$ \\
\hline GMAS9 & 0.56 & -0.15 & -0.14 & 0.64 & -0.19 & 0.06 & 0.19 & 0.25 & 0.26 & 0.14 & 0.06 & I & $1.1 \times 10-16$ \\
\hline GMASIO & 0.69 & -0.33 & -0.22 & -0.16 & -0.15 & 0.05 & 0.25 & -0.10 & -0.41 & 0.13 & 0.23 & 1 & $5.6 \times 10-16$ \\
\hline GMASII & 0.46 & -0.53 & -0.08 & 0.08 & 0.66 & 0.03 & -0.16 & 0.12 & -0.06 & 0.07 & -0.13 & 1 & 1 \\
\hline SS loadings (Initial) & 4.01 & 1.15 & 1.10 & 0.90 & 0.78 & 0.72 & 0.57 & 0.55 & 0.48 & 0.41 & 0.32 & & \\
\hline Proportion of Variance & 0.36 & 0.10 & 0.10 & 0.08 & 0.07 & 0.07 & 0.05 & 0.05 & 0.04 & 0.04 & 0.03 & & \\
\hline$\%$ of variance & $36 \%$ & $10 \%$ & $10 \%$ & $8 \%$ & $7 \%$ & $7 \%$ & $5 \%$ & $5 \%$ & $4 \%$ & $4 \%$ & $3 \%$ & & \\
\hline Cumulative Variance and proportion & 0.36 & 0.47 & 0.57 & 0.65 & 0.72 & 0.79 & 0.84 & 0.89 & 0.93 & 0.97 & 1.00 & & \\
\hline Cumulative variance $\%$ & $36 \%$ & $47 \%$ & $57 \%$ & $65 \%$ & $72 \%$ & $79 \%$ & $84 \%$ & $89 \%$ & $93 \%$ & $97 \%$ & $100 \%$ & & \\
\hline
\end{tabular}

Notes: SS loadings: Eigenvalues (ie, variance explained by that component); h2: Communalities (ie, proportion of common variance among the variables); u2: Uniqueness (ie, the variance that is specific to a particular variable and is not shared with other ones). 
Table 5 Principal Components Analysis After Factors (Components) Retention on the Unrotated and Rotated Conditions

\begin{tabular}{|c|c|c|c|c|c|c|c|c|c|c|}
\hline \multirow[t]{2}{*}{ Items } & \multicolumn{5}{|c|}{ Without Rotation } & \multicolumn{5}{|c|}{ With Varimax Rotation } \\
\hline & $\mathrm{PCI}$ & PC2 & PC3 & h2 & $\mathbf{u} 2$ & $\mathrm{RCI}$ & RC2 & RC3 & h2 & u2 \\
\hline GMASI & 0.56 & 0.10 & 0.60 & 0.69 & 0.31 & 0.11 & 0.17 & 0.80 & 0.69 & 0.31 \\
\hline GMAS2 & 0.51 & -0.08 & 0.62 & 0.65 & 0.35 & 0.18 & -0.01 & 0.78 & 0.65 & 0.35 \\
\hline GMAS3 & 0.48 & 0.47 & -0.23 & 0.50 & 0.50 & 0.12 & 0.70 & 0.06 & 0.50 & 0.50 \\
\hline GMAS4 & 0.51 & 0.41 & -0.33 & 0.53 & 0.47 & 0.21 & 0.70 & -0.01 & 0.53 & 0.47 \\
\hline GMAS5 & 0.58 & 0.52 & 0.01 & 0.61 & 0.39 & 0.08 & 0.70 & 0.32 & 0.61 & 0.39 \\
\hline GMAS6 & 0.70 & -0.24 & -0.29 & 0.64 & 0.36 & 0.74 & 0.28 & 0.08 & 0.64 & 0.36 \\
\hline GMAS7 & 0.72 & 0.04 & 0.19 & 0.55 & 0.45 & 0.41 & 0.35 & 0.52 & 0.55 & 0.45 \\
\hline GMAS8 & 0.77 & -0.07 & -0.05 & 0.60 & 0.40 & 0.60 & 0.37 & 0.33 & 0.60 & 0.40 \\
\hline GMAS9 & 0.56 & -0.15 & -0.14 & 0.36 & 0.64 & 0.54 & 0.23 & 0.14 & 0.36 & 0.64 \\
\hline GMASIO & 0.69 & -0.33 & -0.22 & 0.64 & 0.36 & 0.77 & 0.18 & 0.13 & 0.64 & 0.36 \\
\hline GMASII & 0.46 & -0.53 & -0.08 & 0.50 & 0.50 & 0.68 & -0.14 & 0.13 & 0.50 & 0.50 \\
\hline SS loadings & 4.01 & 1.15 & 1.10 & & & 2.53 & 1.94 & 1.80 & & \\
\hline Proportion of Variance & 0.36 & 0.10 & 0.10 & & & 0.23 & 0.18 & 0.16 & & \\
\hline$\%$ of variance & $36 \%$ & $10 \%$ & $10 \%$ & & & $23 \%$ & $18 \%$ & $16 \%$ & & \\
\hline Cumulative Variance & 0.36 & 0.47 & 0.57 & & & 0.23 & 0.41 & 0.57 & & \\
\hline Cumulative Variance \% & $36 \%$ & $47 \%$ & $57 \%$ & & & $23 \%$ & $41 \%$ & $57 \%$ & & \\
\hline Cumulative Proportion & 0.64 & 0.82 & 1.00 & & & 0.40 & 0.71 & 1.00 & & \\
\hline
\end{tabular}

Abbreviations: PC, Principal component matrix; RC, Rotated component (factor) matrix; h2, Communalities; u2, Uniqueness.

in previous studies, was carried out that also confirmed three factors. This result confirms the three-factor structure reported in the study in which the development and validation of GMAS Scale was conducted. ${ }^{30}$

Moreover, the test-retest reliability was also measured during the pilot study at two weeks intervals. The study showed a 0.894 reliability value, which is acceptable and reliable according to Taber $2017 .{ }^{45}$ Also, the internal consistency of the full test data was calculated. The overall alpha value was 0.82 , which is similar to the study (0.819) in which the Urdu version of GMAS was translated into English version. ${ }^{31}$ However, the overall alpha value is slightly lower in the Nepalese version (0.82) than the original Urdu version $(0.84) .^{30}$ This confirms the internal consistency of the pilot and full-phase study.

This study successfully translated GMAS into Nepalese version and demonstrated to be internally consistent and to have face, cross-cultural and structural validity. This can be a useful tool to explore/investigate medication non- adherence in the Nepalese population with the appropriate translation. Nepal is a low-income country and has a mixed health care system comprising public and private health systems. People's access to and use of medicines in Nepal are affected by their socioeconomic, sociocultural, and socioreligious backgrounds. Medication non-adherence and the consequences of medication non-adherence are complex and poorly understood in Nepal. The Nepalese version (translated and validated) of GMAS can explore the patient, context, cultural and healthcare system-related barriers to medication non-adherence among patients taking chronic disease medications. Chronic diseases such as cardiovascular disease, diabetes, chronic obstructive pulmonary disease (COPD), mental disorders are common causes of mortality in Nepal. ${ }^{50}$ Therefore, this tool (GMAS-Nepalese) will provide a comprehensive method to assess prevalence and factors associated with non-adherence, and assist healthcare workers or concerned bodies in mitigating the problem in the future. 
Table 6 Test-Retest Reliability Analysis of Pilot Test Study

\begin{tabular}{|c|c|c|c|c|}
\hline & $\begin{array}{l}\text { Scale Mean If Item } \\
\text { Deleted }\end{array}$ & $\begin{array}{l}\text { Scale Variance If Item } \\
\text { Deleted }\end{array}$ & $\begin{array}{l}\text { Corrected Item-Total } \\
\text { Correlation }\end{array}$ & $\begin{array}{l}\text { Cronbach's Alpha If Item } \\
\text { Deleted }\end{array}$ \\
\hline GMASI_test & 54.83 & 53.937 & 0.632 & 0.885 \\
\hline GMASI_retest & 54.93 & 54.202 & 0.597 & 0.886 \\
\hline GMAS2_test & 54.73 & 58.340 & 0.441 & 0.891 \\
\hline GMAS2_retest & 54.90 & 58.921 & 0.322 & 0.894 \\
\hline GMAS3_test & 54.47 & 56.051 & 0.682 & 0.885 \\
\hline GMAS3_retest & 54.50 & 56.948 & 0.565 & 0.887 \\
\hline GMAS4_test & 54.47 & 60.740 & 0.150 & $0.897^{*}$ \\
\hline GMAS4_retest & 54.40 & 60.524 & 0.186 & $0.896^{*}$ \\
\hline GMAS5_test & 54.50 & 54.948 & 0.667 & 0.884 \\
\hline GMAS5_retest & 54.47 & 54.809 & 0.691 & 0.883 \\
\hline GMAS6_test & 54.43 & 60.599 & 0.200 & $0.896^{*}$ \\
\hline GMAS6_retest & 54.30 & 59.941 & 0.453 & 0.891 \\
\hline GMAS7_test & 54.63 & 53.964 & 0.745 & 0.882 \\
\hline GMAS7_retest & 54.77 & 54.254 & 0.723 & 0.882 \\
\hline GMAS8_test & 54.43 & 58.047 & $0.46 \mathrm{I}$ & 0.890 \\
\hline GMAS8_retest & 54.40 & 57.834 & 0.574 & 0.888 \\
\hline GMAS9_test & 54.50 & 55.569 & 0.605 & 0.886 \\
\hline GMAS9_retest & 54.47 & 54.947 & 0.677 & 0.884 \\
\hline GMASI0_test & 54.33 & 59.264 & 0.528 & 0.890 \\
\hline GMASI0_retest & 54.33 & 59.747 & 0.443 & 0.891 \\
\hline GMASI0_retest & 54.33 & 59.747 & 0.443 & 0.891 \\
\hline GMASII_test & 54.87 & 57.913 & 0.285 & $0.897 *$ \\
\hline GMASII_retest & 54.83 & 57.454 & 0.420 & 0.891 \\
\hline
\end{tabular}

Notes: Composite Cronbach's alpha: 0.894; number of items: 22. *Items with Cronbach's alpha values greater than the composite alpha value.

\section{Limitations}

This study has some limitations. First, our study was carried out among chronic disease patients from selected pharmacy outlets of Kathmandu valley. A single hospital pharmacy for the pilot study and pharmacies for the full-phase study were conveniently selected. Additionally, the patients visiting those particular pharmacy outlets were conveniently selected based on patient's interest and approval. These factors possibly prevented the true representation of chronic disease patients scattered throughout the nation. Also, in case of patients' incapability to read and write, pharmacy practitioners took their response as proxy. This study has also not evaluated the criterion-related validity, convergent and discriminant validity, and sensitivity analysis, which was conducted in the initial development of GMAS scale and translation into English version by Naqvi et a ${ }^{30,31}$ but, only carried out the exploratory factor analysis, scree plot test and reliability test. Similarly, no correlation studies between the length of treatment and medication adherence were measured. These might be some limitations for better acceptability of this translation, cultural adaptation, and GMAS scale validation. Therefore, it is recommended to do further validation studies among nationwide 
Table 7 Reliability Analysis of Full Test Study

\begin{tabular}{|c|c|c|c|}
\hline Items & $\begin{array}{l}\text { Cronbach's } \\
\text { Alpha If Item } \\
\text { Not Included } \\
\text { or Deleted } \\
\text { (Raw_Alpha) }\end{array}$ & $\begin{array}{l}\text { Correlation } \\
\text { Between } \\
\text { Each } \\
\text { Item (r) }\end{array}$ & $\begin{array}{l}\text { Corrected } \\
\text { Item-Total } \\
\text { Correlation } \\
\text { (r.Drop) }\end{array}$ \\
\hline GMASI & 0.81 & 0.57 & 0.46 \\
\hline GMAS2 & 0.81 & 0.52 & 0.40 \\
\hline GMAS3 & 0.81 & 0.51 & 0.38 \\
\hline GMAS4 & 0.81 & 0.52 & 0.40 \\
\hline GMAS5 & 0.80 & 0.60 & 0.49 \\
\hline GMAS6 & 0.79 & 0.69 & 0.59 \\
\hline GMAS7 & 0.79 & 0.70 & 0.61 \\
\hline GMAS8 & 0.79 & 0.74 & 0.65 \\
\hline GMAS9 & 0.81 & 0.56 & 0.45 \\
\hline GMASIO & 0.80 & 0.67 & 0.57 \\
\hline GMASII & 0.82 & 0.49 & 0.36 \\
\hline
\end{tabular}

Notes: Overall alpha: 0.82; r.drop: correlation of the item with the scale if that item is not included (aka item-rest correlation).

distributed chronic disease patients to strengthen the acceptability and applicability of the tool.

\section{Conclusion}

The general medication adherence scale was successfully translated into the Nepalese language and validated. The validation results indicate that GMAS-Nepalese is a valid and reliable tool to measure medication adherence among Nepalese-speaking patients with chronic illness patients. The tool can be applied to study prevalence and factors associated with medication adherence/non-adherence among patients with chronic diseases in Nepalesespeaking populations.

\section{Data Sharing Statement}

The datasets generated and analysed during the current study are available from the corresponding author on reasonable request. GMAS-Nepalese tool can be obtained contacting corresponding authors.

\section{Ethical Approval and Consent to Participate}

The study was conducted in accordance with the guidelines of declaration of Helsinki. The ethical approval was obtained from the Institutional Review Committee (IRC), Nobel College, Sinamangal, Kathmandu, Province Bagmati, Nepal. Written and verbal informed consent of the participants were taken before collecting their responses.

\section{Acknowledgments}

The authors are thankful to Dr Atta Abbas Naqvi for the permission to translate and validate GMAS into the Nepalese version. Also, thanks to all participants, patients and pharmacies involved in this study.

\section{Author Contributions}

All authors contributed to data analysis, drafting or revising the article, have agreed on the journal to which the article will be submitted, gave final approval for the version to be published, and agreed to be accountable for all aspects of the work.

\section{Funding}

The authors received no financial support for conducting this research work. The authors also acknowledge the support from the University of Birmingham to cover the open access fees for the article.

\section{Disclosure}

The authors declare that they have no competing interests in this work.

\section{References}

1. World Health Organization. Adherence to long-term therapies; 2003. Available from: https://apps.who.int/medicinedocs/en/d/Js4883e/. Accessed August 5, 2021.

2. Kim J, Combs K, Downs J, Tillman Ill F. Medication Adherence: The Elephant in the Room. U.S.Pharmacist; 2018. Available from: https:// www.uspharmacist.com/article/medication-adherence-the-elephant-inthe-room. Accessed August 5, 2021.

3. Haynes RB, Ackloo E, Sahota N, McDonald HP, Yao X. Interventions for enhancing medication adherence. Cochrane Database Syst Rev. 2008;2. doi:10.1002/14651858.CD000011

4. Khan A. Non-Communicable Diseases. In: Mastering Community Medicine. Jaypee Brothers Medical Publishers (P) Ltd.; 2010:161. doi:10.5005/jp/books/11410_18

5. Nepal Health Research Council. Burden of Non-Communicable Diseases in Nepal: An Urgent Need for Actions. Published online 2019. Available from: http://nhrc.gov.np/wp-content/uploads/2019/07/ NCDs-policy-brief.pdf. Accessed May 5, 2021.

6. Shrestha R, Pant A, Shrestha S, et al. Study of medication adherence pattern and factors affecting the adherence in chronic obstructive pulmonary disease. Kathmandu Univ Med J. 2015;13(1):64-70. doi:10.3126/kumj.v13i1.13756

7. Gautam R, Pokharel P. A18646 Adherence to antihypertensive medications among the rural population of Eastern Nepal. J Hypertens. 2018;36:e119-e120. doi:10.1097/01.hjh.0000548479.64171.d2 
8. Shrestha P, Wattanakitkrileart D. Factors influencing medication adherence in Nepalese patients with essential hypertension. Nurs Sci J Thail. 2019;37(3):18-31.

9. Shakya R, Shrestha S, Gautam R, et al. Perceived illness and treatment adherence to hypertension among patients attending a Tertiary Hospital in Kathmandu, Nepal. Patient Prefer Adherence. 2020;14:2287. doi:10.2147/PPA.S270786

10. Iuga MM. Adherence and health care costs. Risk Manag Healthc Policy. 2014;7:35. doi:10.2147/RMHP.S19801

11. Cutler RL, Fernandez-Llimos F, Frommer M, Benrimoj C, GarciaCardenas V. Economic impact of medication non-adherence by disease groups: a systematic review. BMJ Open. 2018;8(1):e16982. doi:10.1136/bmjopen-2017-016982

12. Mongkhon P, Ashcroft DM, Scholfield CN, Kongkaew C. Hospital admissions associated with medication non-adherence: a systematic review of prospective observational studies. BMJ Qual Saf. 2018;27 (11):902-914. doi:10.1136/bmjqs-2017-007453

13. Roebuck MC, Liberman JN, Gemmill-Toyama M, Brennan TA. Medication adherence leads to lower health care use and costs despite increased drug spending. Health Aff. 2011;30(1):91-99. doi:10.1377/ hlthaff.2009.1087

14. Simpson SH, Eurich DT, Majumdar SR, et al. A meta-analysis of the association between adherence to drug therapy and mortality. $B M J$. 2006;333(7557):15. doi:10.1136/bmj.38875.675486.55

15. Kleinsinger $\mathrm{F}$. The unmet challenge of medication nonadherence. Perm J. 2018;22:1-3. doi:10.7812/TPP/18-033

16. Lehmann A, Aslani P, Ahmed R, et al. Assessing medication adherence: options to consider. Int J Clin Pharm. 2014;36(1):55-69. doi:10.1007/s11096-013-9865-x

17. Garfield S, Clifford S, Eliasson L, Barber N, Willson A. Suitability of measures of self-reported medication adherence for routine clinical use: a systematic review. BMC Med Res Methodol. 2011;11(1):149. doi:10.1186/1471-2288-11-149

18. Nguyen T-M-U, La CA, Cottrell N. What are validated self-report adherence scales really measuring?: a systematic review. $\mathrm{Br} J$ Clin Pharmacol. 2014;77(3):427-445. doi:10.1111/bcp.12194

19. Government of nepal $\mathrm{M}$ of $\mathrm{H}$ and P. Nepal national health accounts 2012/13 to 2015/16. 2018:123. Available from: www.searo.who.int/ entity/nepal/documents/nepal_nha_2012_13_2015_16_mohp_june_ 2018.pdf. Accessed August 5, 2021.

20. Xinhua. COVID-19 could push nearly one-third of Nepal's population below poverty line: world Bank report - xinhua. English.news. cn. Xinhua; 2020. Available from: http://www.xinhuanet.com/eng lish/2020-07/23/c_139235741.htm. Accessed January 25, 2021.

21. Khanal S, Veerman L, Nissen L, Hollingworth S. Forecasting the amount and cost of medicine to treat type 2 diabetes mellitus in Nepal using knowledge on medicine usage from a developed country. J Pharm Heal Serv Res. 2019;10(1):91-99. doi:10.1111/jphs.12265

22. Bhandari B, Bhattarai M, Bhandari M, Ghimire A, Pokharel PK, Morisky DE. Adherence to antihypertensive medications: population based follow up in Eastern Nepal. J Nepal Health Res Counc. 2015;13(29):38-42.

23. Morisky DE, Ang A, Krousel-Wood M, Ward HJ. Predictive validity of a medication adherence measure in an outpatient setting. $J$ Clin Hypertens. 2008;10(5):348-354. doi:10.1111/j.1751-7176.2008.07572.x

24. Svarstad BL, Chewning BA, Sleath BL, Claesson C. The brief medication questionnaire: a tool for screening patient adherence and barriers to adherence. Patient Educ Couns. 1999;37(2):113-124. doi:10.1016/S0738-3991(98)00107-4

25. Kripalani S, Risser J, Gatti ME, Jacobson TA. Development and evaluation of the Adherence to Refills and Medications Scale (ARMS) among low-literacy patients with chronic disease. Value Health. 2009;12(1):118-123. doi:10.1111/J.1524-4733.2008.00400.X

26. Thompson K, Kulkarni J, Sergejew AA. Reliability and validity of a new Medication Adherence Rating Scale (MARS) for the psychoses. Schizophr Res. 2000;42(3):241-247. doi:10.1016/S0920-9964(99)00130-9
27. Kim MT, Hill MN, Bone LR, Levine DM. Development and testing of the Hill-bone compliance to high blood pressure therapy scale. Prog Cardiovasc Nurs. 2000;15(3):90-96. doi:10.1111/j.17517117.2000.tb00211.x

28. Naqvi AA, Hassali MA. Limitations in contemporary self-reported medication adherence questionnaires: the concept and design of the General Medication Adherence Scale (GMAS) originating from a developing country. Curr Med Res Opin. 2019;35(1):1-2. doi:10.1080/03007995.2018.1526169

29. Forbes CA, Deshpande S, Sorio-Vilela F, et al. A systematic literature review comparing methods for the measurement of patient persistence and adherence. Curr Med Res Opin. 2018;34(9):1613-1625. doi:10.1080/03007995.2018.1477747

30. Naqvi AA, Hassali MA, Rizvi M, et al. Development and validation of a novel General Medication Adherence Scale (GMAS) for chronic illness patients in Pakistan. Front Pharmacol. 2018;9:(OCT):1-12. doi:10.3389/fphar.2018.01124

31. Naqvi AA, Hassali MA, Jahangir A, Nadir MN, Kachela B. Translation and validation of the English version of the general medication adherence scale (GMAS) in patients with chronic illnesses. J Drug Assess. 2019;8(1):36-42. doi:10.1080/ 21556660.2019.1579729

32. Shrestha B, Ferdoush Z, Rabbi F, Hossain A. Adherence to medications among Nepali hypertensive population: a hospital-based cross-sectional study. Biomed Res Clin Pract. 2018;3(1):1-4. doi:10.15761/BRCP.1000159

33. Tan CS, Hassali MA, Neoh CF, Saleem F, Cultural Adaptation HR. Linguistic validation of the beliefs about medicines questionnaire in Malaysia. Value Health Reg Issues. 2018;15:161-168. doi:10.1016/j. vhri.2017.12.010

34. Shrestha S, Sapkota B, Thapa S, Khanal KCB. Translation, cross-cultural adaptation and validation of Patient Satisfaction with Pharmacist Services Questionnaire (PSPSQ 2.0) into the Nepalese version in a community settings. PLoS One. 2020;15(10):e0240488. doi:10.1371/journal.pone. 0240488

35. Embassy of India K. About India-Nepal relations. Avialable from: https://www.indembkathmandu.gov.in/page/about-india-nepalrelations/. Accessed August 5, 2021.

36. Bolarinwa O. Principles and methods of validity and reliability testing of questionnaires used in social and health science researches. Niger Postgrad Med J. 2015;22(4):195. doi:10.4103/1117-1936.173959

37. Wild D, Alyson G, Mona M, et al. Principles of good practice for the translation and cultural adaptation process for Patient-Reported Outcomes (PRO) measures. Value Heal. 2005;8(2):95-104.

38. Conference I, Eighth I, Est R. Kathmandu Metropolitan City, Nepal. 2014. Available from: https://www.uncrd.or.jp/content/documents/ 20488EST-City-Report_Nepal-Kathmandu.pdf. Accessed January 25, 2021.

39. AlQarni K, AlQarni EA, Naqvi AA, et al. Assessment of medication adherence in Saudi patients with Type II diabetes mellitus in Khobar City, Saudi Arabia. Front Pharmacol. 2019:10. doi:10.3389/ fphar.2019.01306.

40. Mir SA, Bhat MU-D, Shakeel D. Self-reported adherence to pharmacotherapy in cancer patients. Int J Basic Clin Pharmacol. 2020;9 (6):854. doi:10.18203/2319-2003.ijbcp20202170

41. Team RC. $R$ : A Language and Environment for Statistical Computing. Vienna, Austria: $\mathrm{R}$ Foundation for Statistical Computing; 2020. Available from: https://www.r-project.org/. Accessed August 5, 2021.

42. Costello AB, Osborne JW. Best practices in exploratory factor analysis: four recommendations for getting the most from your analysis. Pract Assessment Res Eval. 2005;10:7. doi:10.7275/jyj1-4868

43. Osborne JW, Costello AB. Sample size and subject to item ratio in principal components analysis. Pract Assessment Res Eval. 2004;9:11. doi:10.7275/ktzq-jq66 
44. Naqvi AA, Mahmoud MA, AlShayban DM, et al. Translation and validation of the Arabic version of the General Medication Adherence Scale (GMAS) in Saudi patients with chronic illnesses. Saudi Pharm J. 2020;28(9):1055-1061. doi:10.1016/j. jsps.2020.07.005

45. Taber KS. The use of Cronbach's Alpha when developing and reporting research instruments in science education. Res Sci Educ. 2018;48 (6):1273-1296. doi:10.1007/s11165-016-9602-2

46. IBM Knowledge Center. KMO and Bartlett's test. Available from: https://www.ibm.com/support/knowledgecenter/en/SSLVMB_subs/ statistics_casestudies_project_ddita/spss/tutorials/fac_telco_kmo_01. html. Accessed August 5, 2021.

47. Kaiser HF. An index of factorial simplicity. Psychometrika. 1974;39 (1):31-36. doi:10.1007/BF02291575
48. Naqvi AA, Hassali MA, Rizvi M, et al. Validation of the general medication adherence scale in Pakistani patients with rheumatoid arthritis. Front Pharmacol. 2020;11(July):1-11. doi:10.3389/ fphar.2020.01039

49. Bryman A, Cramer D. Quantitative Data Analysis with SPSS 12 and 13. Routledge; 2004; doi:10.4324/9780203498187

50. Nepal Health Research Council (NHRC) Ministry of Health and Population (MOHP), Monitoring Evaluation and Operational Research (MEOR) Nepal. Nepal Burden of Disease 2017; 2017.

\section{Publish your work in this journal}

Patient Preference and Adherence is an international, peer-reviewed, open access journal that focusing on the growing importance of patient preference and adherence throughout the therapeutic continuum. Patient satisfaction, acceptability, quality of life, compliance, persistence and their role in developing new therapeutic modalities and compounds to optimize clinical outcomes for existing disease states are major areas of interest for the journal. This journal has been accepted for indexing on PubMed Central. The manuscript management system is completely online and includes a very quick and fair peer-review system, which is all easy to use. Visit http:// www.dovepress.com/testimonials.php to read real quotes from published authors. 